\title{
Practical DC Induction Cooker Design and Implementation
}

\author{
${ }^{1}$ Yasir Uthman, ${ }^{2}$ Grace Oletu (PhD) \& Olumide Longe PhD \\ ${ }^{182}$ American University of Nigeria, Yola, Nigeria \\ Academic City University College Accra, Ghana \\ E-mails: yasir.uthman@aun.edu.ng \\ grace.oletu@aun.edu.ng; olumide.longe@acity.edu.gh \\ Phones: ${ }^{1+2348022448784 ;{ }^{2}+2348057202980 ;+23359579930}$
}

\begin{abstract}
Induction heating is a well-known Technology that is usually used for cooking appliances because of its highenergy efficiency. This paper presents a practical design of a low voltage induction cooker, with a centretapped, and parallel resonant converter. The process is fully analyzed and the practical implementation has been put in place to create a 500W - $1 \mathrm{KW}$ low voltage induction cooker. This was done through a series of experiments on the effect of eddy current and electromagnetic induction. The results and performance are shown for a prototype induction cooking system. It provides a substantial solution to the cooking problem in most developing countries.
\end{abstract}

Keywords - Resonant converter, induction cooking, coil, phase angle, frequency tracking

Proceedings Reference Format

Yasir Uthman, Grace Oletu \& Olumide Longe (2021): Practical DC Induction Cooker Design and Implementation. Proceedings of the 27th iSTEAMS Multidisciplinary Innovations \& Technology Transfer (MINTT) Conference. Academic City University College, Accra, Ghana. June, 2021. Pp 231-238 www.isteams.net/ghana2021. DOI - https://doi.org/ 10.22624/AIMS/iSTEAMS-2021/N27P19

\section{INTRODUCTION}

Induction heating is a contactless technique of generating heat energy in a conductive material by producing eddy current losses in the work piece from an external variable high-frequency power source. Over the last ten years, induction cooking is much used, because of its advantages [1] compared to conventional heating system (resistance, gas, etc.), in particular direct heating of pan without thermal inertia. All induction heating $(\mathrm{IH})$ applied systems are developed using electromagnetic induction which was first discovered by Michael Faraday in 1831[2]. Electromagnetic induction refers to the phenomenon by which electric current is generated in a closed circuit by the fluctuation of current in another circuit placed next to it. The basic principle of induction heating, which is an applied form of Faraday's discovery, is the fact that AC current flowing through a circuit affects the magnetic movement of a secondary circuit located near it [3]. The fluctuation of current inside the primary circuit provided the answer as to how the mysterious current is generated in the neighbouring secondary circuit. Faraday's discovery led to the development of electric motors, generators, transformers, and wireless communications devices [4]. Its application, however, has not been flawless. Heat loss, which occurs during the electromagnetic induction process, was a major headache undermining the overall functionality of a system. This heat loss, could be turned into productive heat energy in an electric heating system. 


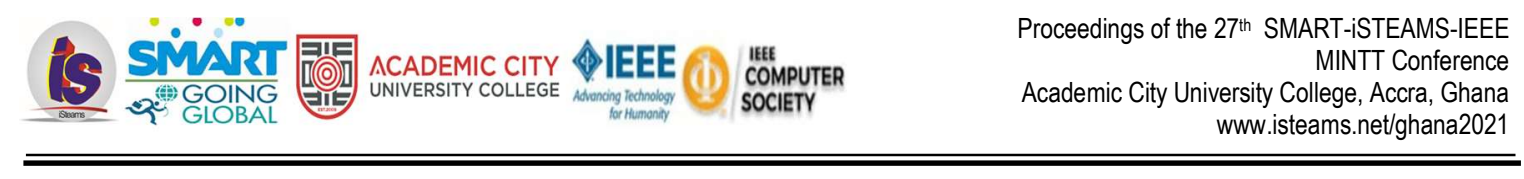

Many industries have benefited from this new breakthrough by implementing induction heating for furnacing, quenching, and welding. In these applications, induction heating has made it easier to set the heating parameters without the need of an additional external power source. This substantially reduces heat loss while maintaining a more convenient working environment. Absence of any physical contact to heating devices precludes unpleasant electrical accidents [3]. High energy density is achieved by generating sufficient heat energy within a relatively short period of time

Induction cooking has become of widespread use because of some specific features such as safety, heating speed and efficiency. These are mainly due to the induction cooking working principle, which is based on local heating generated by eddy current at the bottom of the pan. New types of manufacturing processes have made it possible to obtain multi-layer vessel structures, enjoying a very efficient heating behaviour. The main goal of this technology is to achieve a uniform cooking temperature and a high magnetic coupling [3] [5].Beside several advantages there are still some issues such as high cost and power consumption. Research efforts up to now have consisted on one hand in optimizing the induction system, looking for new layouts of both inductor and vessel [3] [6-10] and, on the other hand, in optimizing the performance of the power supply [11-13].

Basically a domestic induction appliance consists of a high frequency (HF) inductor, i.e. a copper Litz wire tape placed below the cooking surface, and a metallic vessel, which may be made of different layers of magnetic stainless steel and highly conductive materials like aluminium or copper. [3] [14][15]. Copper is an excellent conductor of heat, and copper pans are often used to heat sauces and dishes at strictly controlled temperatures. $(\mathrm{IH})$ of non-ferro magnetic pans can be achieved through various approaches, such as the use of an induction adapter, a thin slab [16], or a reducer plate [17], multiple induction coils [18], [19], and high current and highfrequency resonant converters [3] [16], [20]-[22].

The power electronic supply consists of ac/dc rectifier, a bus filter, and a resonant inverter [8]. In resonant inverters zero-voltage or zero-current switching are attained when the R-L-C circuit, representing the induction system and the matching capacitance, is resonating. In this condition power switching losses are minimized enabling high frequency operations, with limited size and cost of the device. In this framework the analysis of the equivalent impedance of the coupled inductor-vessel system becomes mandatory in order to obtain an optimal design of supply systems [3] [14][15].

The paper is arranged as follows. Section II provided the background of Induction Cooker Design and working principle. Section III presented the results obtained from the Induction Cooker Design. Section IV concluded the paper.

\section{INDUCTION COOKER DESIGN AND WORKING PRINCIPLE}

The design is a 24V DC cooker that will be operated with batteries or solar panel. It might involve the use of two $12 \mathrm{~V}$ batteries, a charge controller, and two pieces of $250-300 \mathrm{~W}$ solar panels. The typical design will provide heating power ranging from $500 \mathrm{Ws}$ to $1 \mathrm{KWs}$. The proposed design comprises of many components such as the resonant circuit, LCD, pot detector, temperature sensor, switching components, and the microcontroller that serves as the main control of The Proposed system process work is divided into the following sections: 


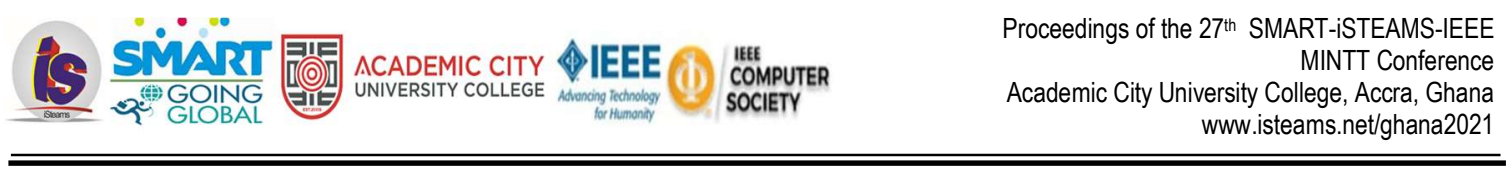

\section{Resonant Converter Circuit}

The resonant converter circuit consists of a spiral twisted coil and a tank capacitor. The coil is made up of multiple strands of copper twisted together to reduce the skin effect.

\section{LCD Display}

Liquid crystal display is often used to provide an interface in induction cookers. In this design, a 16-bit LCD is used because it is cheap and easy to use. It is a parallel LCD that can display up to 16 characters and that can accommodate almost all our needs.

\section{Pot detector}

An experiment carried out by [23] shows that induction cookers that do not have a pot detection technology might have a high risk of causing fire because they can't detect when a wrong cooking vessel is put on it such as a small can which might have fuel on it. It necessitates the need of inputting a pot detection sensor in our design for the safe operation of the cooker. The essence of the pot detector is to be able to detect ferromagnetic pots, non-ferromagnetic pots, and small or wrongly-placed pots.

\section{Temperature Sensor}

The temperature sensor will be placed on the heatsink of the switching Mosfet transistors so that it can monitor the temperature of the Mosfet. Through the temperature sensor, the DC fan speed will be controlled. In this design, the fan will start when the temperature reaches 40 degrees Celsius and the fan speed will be varied based on the increase of the temperature. If the temperature exceeds 40 degrees Celsius, the system will shut down. A single NTC glass encapsulated thermistor is used which is placed near the heatsink so that it can capture the heat produced by the Mosfets.

\section{Buzzer Alarm}

The buzzer used in this design is an electromagnetic buzzer which is rated at $12 \mathrm{~V}$. The electromagnetic buzzer is used because it produces greater sound than a piezo-electric buzzer. The buzzer serves as an output device for errors by beeping sound. It will indicate a pot detection error, an error, and a low battery indication.

\section{Microcontroller Unit (MCU)}

Even though in his [24] the use of the S08PT chip for induction cooking control, its unavailability necessitates us to use [25] microcontrollers. It was a good program designed for induction cooker control and operations [24]. We will be using the pic microcontroller for controlling the cooker. The microcontroller unit is the central control unit of the system. It controls the system operations such as accepting user input, providing feedback through the LCD, and executing the command inputted by the user. It uses a chain of command codes that were burnt in the microcontroller chip. It accepts the data analog data signal from components such as thermistors, comparators and converts them to a digital signal via the analog-digital converter module before processing the data and executing the command. 


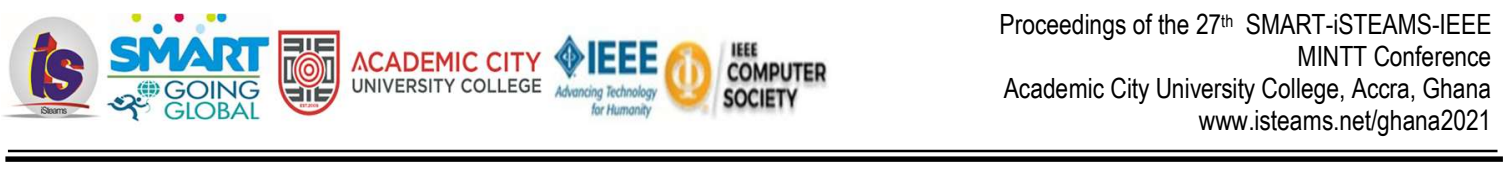

\section{EXPERIMENTAL RESULTS}

After designing and constructing the solar induction cooker, the performance of it was tested and compared with that of the electric cooker using the following experiment

\section{Experiment One: Boiling water}

This experiment assesses the effectiveness of DIC by boiling water on it. The time it takes from powering on the device to when the water starts boiling. The same process was done using conventional electric cooker. The experiment was repeated for five (5) trials, conducted with opened and closed lid pots. The result for each setup is tabulated in Table 1 and Table 2.

\section{Experiment Variables}

1. Amount of water (1liter or 4 cups)

2. The container (same)

3. The heat source (DIC and Electric Cooker)

4. The altitude (same)

Table 1: Boiling water with closed lid pot

\begin{tabular}{|c|c|c|c|}
\hline \multirow[t]{2}{*}{ Trials } & \multirow[t]{2}{*}{ Specimen } & \multicolumn{2}{|l|}{ Time (seconds) } \\
\hline & & DC Induction cooker & $\begin{array}{l}\text { Conventional } \\
\text { Electric Cooker }\end{array}$ \\
\hline 1 & Water & 295 & 263 \\
\hline 2 & Water & 312 & 245 \\
\hline 3 & Water & 364 & 289 \\
\hline 4 & Water & 379 & 232 \\
\hline
\end{tabular}

Data obtained from the experiment of boiling water and egg frying shows that our cooker is slightly slower than the AC induction cooker due to the following limitations. Unlike the commercial induction cooker which coil was wound using the machine, in our model we use hands to wind the strands of the coil including making the spiral shape and that result in uneven space between the coil which affects the inductance and the performance of the cooker

Our limitation includes a lack of a ferrite base for our coil which serves as magnetic field concentrators. The ferrite core which is placed at the backside of the coil has a high permeability to the magnetic field and it, therefore, serve as a shield that stops the magnetic field from heating the electronic components under the coil and concentrating the magnetic field upward to heat the pan. The ferrite core also lowers the coil inductance including the coil $\mathrm{Q}$ and the load. The commercial induction cooker was able to beat our cooker due to the ferrite-based coil. However, our cooker is faster and more reliable than conventional heating element-based cooker and it has the following advantage compared to either the AC, conventional element cooker or the traditional method of cooking which causes environmental pollution. Lack of reliable cooking energy in developing Countries. 


\section{CONCLUSIONS}

In this paper the induction cooker is designed to replace ordinary stove plates. The proposed DC induction cooker has been developed and the performance is good. Unlike conventional electric cookers that cannot be used in the rural area, the DC induction cooker can be used in rural areas where there is no electricity The DC induction cooker is faster and more reliable than conventional cookers unlike firewood, kerosene, and gas that affect the health of the user, the DC induction has no health effect on the user and the environment generally.

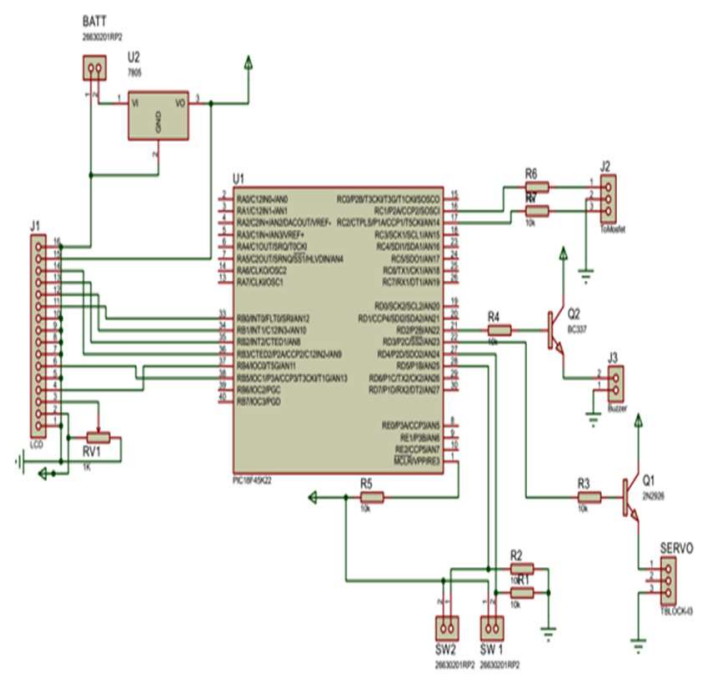

Figure 1: Schematic Digital Control Circuit Diagram for Proposed DC Cooker

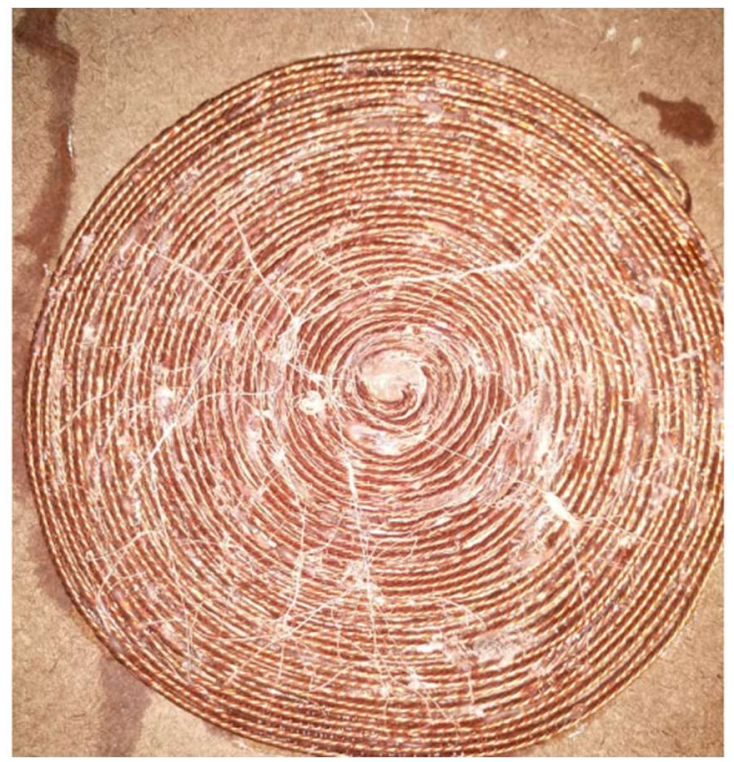

Figure 2: Induction Coil 


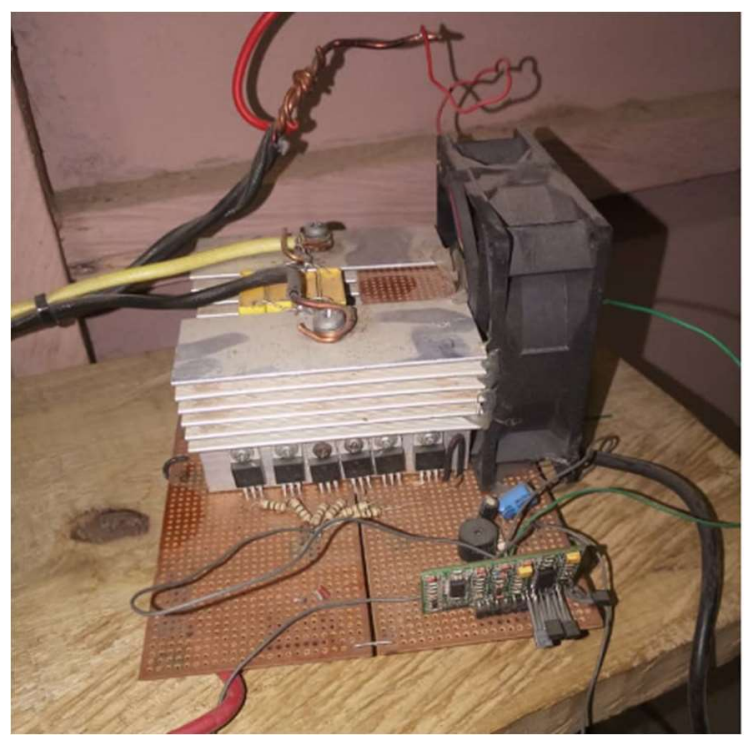

Figure 3: IGBT Coil Driver Circuit

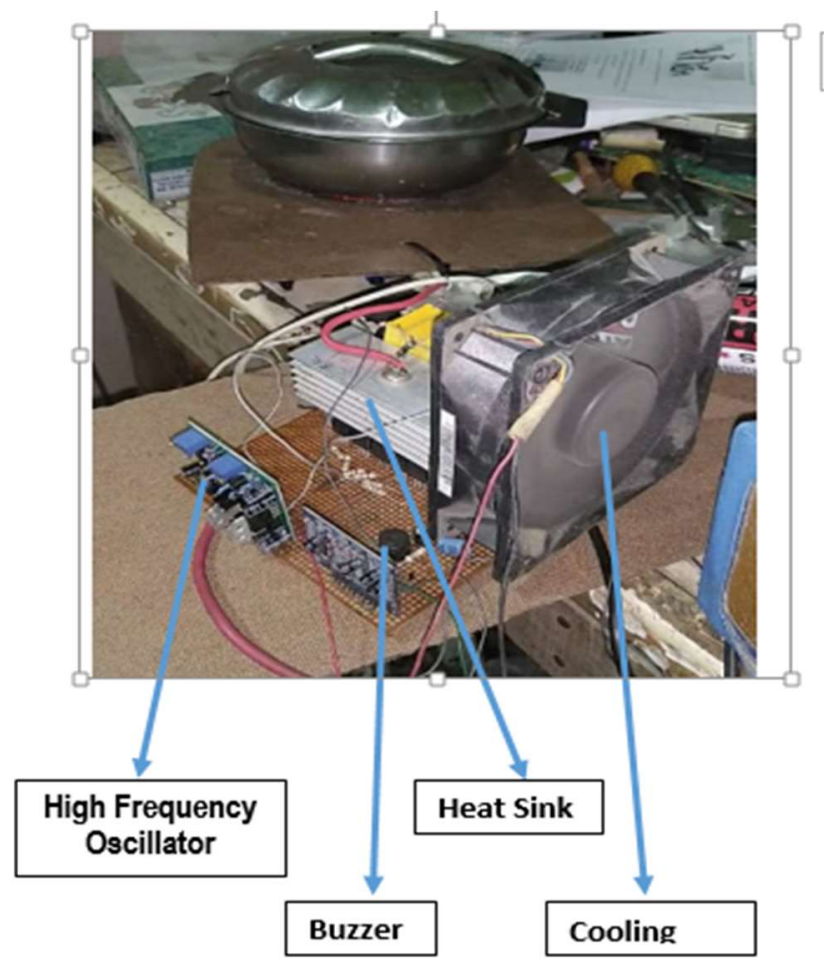

Figure 4: Circuit Setup 


\section{REFERENCES}

[1] A. Z. A. Kansab, M. Feliachi, "Modeling and optimization of induction cooking by the use of magnetothermal finite element analysis and genetic algorithms," FEE Engineering Springer, vol. 7 (3) (2012) 312-317., 2012.

[2] P. J. H. J. Acero, J.M. Burdio, R. Alonso, L.A. Barragan,, "Simple resistance calculation in Litz-Wire planar windings for induction cooking appliances," IEEE Trans. on Magnetics 41 (4) (2005) 12801288., 2005.

[3] Al-Shaikhli, A. K. M., and Amanoeel Thomas Meka. "Design and implementation of practical induction heating cooker." International Journal of soft computing and Engineering (IJSCE) 4.4 (2014): 73-76.

[4] J. C. S. Y. Duterrail, Ph.masse and J.L. coulomb, "Non- Linear Complex Finite Element Analysis of Electromagnetic Field in Steady-State AC Devices," IEEE Trans. On Magnetics, Vol.Mag-20, no.4, 1984.

[5] K. C. J.K. Byun, H.S. Roh, S.Y. Hahn, "Optimal design procedure for a practical induction heating cooker," IEEE Trans. Mag. 36 (4) (2000) 1390-1393., 2000.

[6] H.-C. C. a. K.-H. Huang, "Finite element analysis of coupled electromagnetic and thermal fields within a practical induction heater," International Journal of Applied Electromagnetics and Mechanics, vol. 28, pp. 413-427., 2008.

[7] U. Has, "Temperature control for food in pots on cooking hobs," IEEE Trans. on Industrial Electronics, vol. vol. 46, issue 5, pp. 1030-1034, 1999.

[8] J. Acero et al, "Domestic induction appliances," IEEE Industry Applications Magazine, pp. 39-47., 2010.

[9] S. K. G. Cerri, and V.M. Pimiani, "Modelling of Litz-wire planar winding geometry for an accurate reactance evaluation," Sci. Meas. Technol., vol. 4, issue 4, pp. 214-219., 2010.

[10] S. K. V.M. Primiani, and G. Cerri, "Rigorous electromagnetic model of an induction cooking system," IET Sci. Meas. Technol., vol. 6, issue 4, pp. 238-246, 2012.

[11] F. Forest et al, "Frequency-Synchronized Resonant Converters for the Supply of Multiwinding Coils in Induction Cooking Appliances," IEEE Trans. on Industrial Electronics, vol. 54, issue 1, pp. 441-452., 2007.

[12] H. Sarnago et al, "Modulation Scheme for Improved Operation of a RB-IGBT Based Resonant Inverter Applied to Domestic Induction Heating," IEEE Trans. on Industrial Electronics, vol. 60, issue 5, pp. 2066-2073., 2013.

[13] O. Lucia et al, "Load-Adaptive Control Algorithm of Half-Bridge Series Resonant Inverter for Domestic Induction Heating," IEEE Trans. on Industrial Electronics, vol. 56, issue 8, pp. 3106-3116, 2009.

[14] C. Carretero et al, "Temperature influence on equivalent impedance and efficiency of inductor systems for domestic induction heating appliances," Proc. of IEEE Applied Power Electronic Conference, pp. 153-158., 2007

[15] Al-Shaikhli, A.K.M. and Meka, A.T., 2014. Design and implementation of practical induction heating cooker. International Journal of soft computing and Engineering (IJSCE), 4(4), pp.73-76

[16] J. Acero, I. Lope, J. M. Burdio, C. Carretero, and R. Alonso, "Performance evaluation of graphite thin slabs for induction heating domestic applications," IEEE Trans. Ind. Appl., vol. 51, no. 3, pp. 2398_2404, May 2015.

[17] A. Amrhein, "Induction heating of aluminum cookware," M.S. thesis, Elect. Eng., Virginia Tech., Blacksburg, VA, USA, 2015. 
[18] Panasonic Takes Induction to the Next Level. [Online]. Available:https://www.mountainhighappliance.com/cooking/cooktops/electriccooktops/KYMK3500/

[19] W. Han, K. T. Chau, Z. Zhang, and C. Jiang, "Single-source multiplecoil homogeneous induction heating," IEEE Trans. Magn., vol. 53, no. 11, pp. 1_6, Nov. 2017.

[20] W. Han, K. T. Chau, and Z. Zhang, "Flexible induction heating using magnetic resonant coupling," IEEE Trans. Ind. Electron., vol. 64, no. 3, pp. 1982_1992, Mar. 2017.

[21] H.-P. Park, M. Kim, J.-H. Jung, and H.-S. Kim, "Load adaptive modulation method for all-metal induction heating application," in Proc. IEEE Appl. Power Electron. Conf. Expo. (APEC), San Antonio, TX, USA, Mar. 2018, pp. 3486_3490.

[22] T. Hirokawa, E. Hiraki, T. Tanaka, M. Okamoto, and M. Nakaoka, The practical evaluations of timesharing high-frequency resonant soft switching inverter for all metal IH cooking appliances," in Proc. IECON-38th Annu. Conf. IEEE Ind. Electron. Soc., Montreal, QC, Canada, Oct. 2012, pp. 3302_3307.

[23] Wong, K. K., and N. K. Fong. 2013. "Experimental Study of Induction Cooker Fire Hazard." Procedia Engineering 52: 13-22.

[24] Leo Pan, Dennis Lui, T.C. Lun, Designing an Induction Cooker Using the S08PT Family, Freescale Semiconductor, Inc 2014.

[25] Microchip, "PIC18F45K22 Data Sheet 28/40/44-Pin Enhanced Flash Microcontrollers". 2020. 